\title{
$S$
}

S $\quad$ e Estudos Semióticos - número um (2005)

\section{Um olhar semiótico sobre as várias maneiras de desenhar um cubo}

\author{
Adriane Ribeiro Andalo TENUTA (UNESP, Bauru)
}

RESUMO: Tendo por base os estudos semióticos de Algirdas Julien Greimas e a Semiótica Plástica ou Planar desenvolvida por Jean-Marie Floch, que tem por objeto a imagem fixa manifestada sobre uma superfície bidimensional, tratamos de "ler" o desenho infantil como linguagem não-verbal, construída sobre um plano, articulada plasticamente, com o objetivo de produzir sentido.

PALAVRAS-CHAVE: Desenho infantil, linguagem, não-verbal, Semiótica.

ABSTRACT: Based upon semiotic studies of Algirdas Julien Greimas and on Plastic Semiotics developed by Jean-Marie Floch, which deals with pictures on a plane, we try to "read" children's drawing as a non-verbal language, built over a plane, plastically articulated to produce meaning.

KEY-WORDS: drawing, childhood, language, non-verbal, Semiotics. 


\section{Introdução}

A presente pesquisa a respeito do desenho infantil seguiu o caminho inverso da teoria histórico-cultural defendida por FERREIRA (1998:16) a qual afirma que os desenhos infantis não podem ser considerados como códigos em si mesmos, pois necessitam do diálogo entre a criança e o adulto intérprete como condição fundamental para serem decifrados, uma vez que os significados das figurações só podem ser explicitados por palavras. Ao contrário, tratamos de demonstrar que os desenhos são códigos em si mesmos, que podem ser decifrados, já que os significados estão na própria manifestação figurativizada (iconizada), enquanto linguagem não-verbal, impressa sobre uma superfície plana, como pretendem os estudos do Groupe $\mu$ e a semiótica planar ou pictural de Jean-Marie Floch.

É certo que toda criança desenha. Como os gestos, o choro, o riso e a fala, o desenho é a primeira forma gráfica de expressão e comunicação dos seres humanos. Ao desenhar, a criança, por volta de 3 anos de idade, começa a exercitar sua habilidade para categorizar tudo que está fora de seu corpo, deixando marcas (rabiscos, garatujas) sobre qualquer superfície plana. Conforme as palavras de ASSIS SILVA (1995:71-72), com este trabalho pretendemos apresentar o discurso desenhado pela criança, como uma instância simbólica, na qual encontram-se interligados, o mundo que ela vivencia, a capacidade de sentir e de categorizar (como ser humano) e a linguagem não-verbal do desenho.

\section{A escolha pela semiótica de origem greimasiana}

Durante o curso de Mestrado (2000/2002, UNESP/Bauru), dediquei-me ao estudo da semiótica de A. J. Greimas, porque me pareceu que essa teoria poderia responder indagações a respeito do como as crianças, através de desenhos, manifestam sua vivência, sensibilidade e conhecimento de mundo. Além disso, minha própria formação de professora de línguas, aposentada desde 1996, indicava o caminho conhecido da Lingüística, na esteira de Ferdinand de Saussure, autor que embasa a semiótica greimasiana a partir da dicotomia significante vs significado.

Diferente da semiótica americana elaborada por Charles Sanders Peirce (1839-1914), que segue uma linha filosófica e lógica, segundo BERTRAND (2003: 15), a semiótica francesa se interessa pelo "parecer do sentido" e não pelo signo empírico e suas codificações. Na verdade, essa teoria procura desvendar "o sentido que o signo suscita, articula e que o atravessa em suas relações estruturais, subjacentes e reconstruíveis, que produzem significação":

Portanto, a semiótica greimasiana é uma metodologia de caráter científico que procura descrever as relações que podem ser encontradas sob os signos e entre os 
signos, em busca de unidades significantes (interseções de relações), que subjazem à manifestação. Além disso, segundo o Dicionário de Semiótica (s/d: 226/335), diferente da semiologia que trata a imagem como uma mensagem constituída de signos icônicos, a semiótica planar estuda o significante bidimensional para mostrar as coerções gerais que a natureza de tal plano de expressão impõe à manifestação da significação, e para depreender as formas semióticas mínimas, comuns ao domínio do visual.

Pareceu-me então que quando uma criança desenha e sabe-se que se trata de cavalos, a semiótica planar deveria analisar aquele desenho, a fim de descobrir os procedimentos topológicos (localização no espaço), eidéticos (formas) e cromáticos (cores), que foram utilizados para que tivesse o significado que tem: desenho de cavalos. Vejamos a descrição desse tipo de análise, a partir de um desenho infantil coletado no JCCriança, encarte que sai aos domingos no Jornal da Cidade de Bauru:

\section{(Figura 1.2) JCCriança, Gabriela, 5 anos}

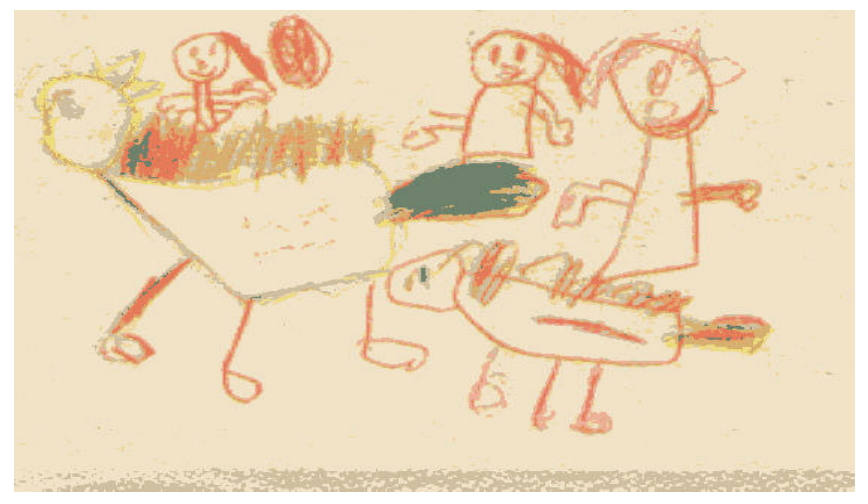

Estamos supondo que os animais desenhados nessa cena são cavalos. Mas como podemos saber que a menina Gabriela desenhou cavalos e não cachorros? A semiótica ajuda a responder essa pergunta quando diz que o significado está nas diferenciações que são impostas ao significante a fim de constituir um significado: as crianças desse desenho não possuem pernas como seria de se esperar, elas parecem flutuar sobre os dois animais, o que leva a crer que elas estejam montadas sobre eles. Além disso, a presença de traços sobre o dorso do animal como se fosse crina e $o$ cabelo das meninas como se estivessem ao vento, também podem nos levar a dizer que temos aí dois cavalos e três crianças ou pessoas. 
Ainda podemos verificar que as figuras são vazadas e estão em primeiro plano. O desenho é monocromático, isto é, todo em laranja, notando-se apenas umas manchas verdes. Além disso, os cavalos possuem somente três pernas, como se o observador não pudesse ver a quarta, que deve ser inferida pelo observador, como costuma acontecer em muitos desenhos de crianças pequenas como Gabriela. Apesar do detalhamento das cores e formas, essas expressões da manifestação não chegam a acrescentar outros significados ao desenho.

Assim exemplificada, a aplicação da semiótica aos desenhos parece muito simples, mas as complicações surgem quando consideramos que Greimas recorreu às definições de plano de expressão e plano de conteúdo, subdividindo-os em substância e forma, a partir de Louis Hjelmslev, para estudar a significação dos textos, dedicando-se, quase que exclusivamente, ao plano de conteúdo do texto literário, verbal, deixando de lado os textos não-verbais e o plano de expressão. Nas palavras de PIETROFORTE (2004:8):

[...]Colocado de lado em um primeiro momento do desenvolvimento teórico da semiótica, o plano da expressão passa a ser tomado como objeto de estudo quando uma categoria do significante se relaciona com uma categoria do significado, ou seja, quando há uma relação entre uma forma da expressão e uma forma do conteúdo. [...] Essa relação entre expressão e conteúdo é chamada de semi-simbólica. Ela é arbitrária porque é fixada em determinado contexto, mas é motivada pela relação estabelecida entre os planos da linguagem.

Desse modo, fomos em busca de outras teorias semióticas que pudessem nos ajudar e chegamos ao Groupe $\mu$ e aos estudos de Jean-Marie Floch, principalmente na obra Petites mythologies de l'oeil et de l'esprit (1985), em que o autor desenvolve o conceito de semi-simbolismo para aplicá-lo ao estudo de fotografias, de pinturas, de arquitetura, de história em quadrinhos e de propaganda publicitária. Isso quer dizer que não existe uma semiótica que tenha tratado apenas do desenho, mas existe, com o Groupe $\mu$ uma semiótica que trata do signo visual e com Floch, uma semiótica planar, aplicada à imagem que se apresenta sobre uma superfície bidimensional.

FLOCH (1985: Anexo) escreveu que:

[...] Para a semiótica, o sentido resulta da reunião, na fala, na escrita, no gesto ou no desenho, dos dois planos que toda linguagem possui: o plano da expressão e o plano do conteúdo. O plano da expressão é o plano onde as qualidades sensíveis que uma linguagem possui para se manifestar, são selecionadas 
e articuladas entre si por variações diferenciais. O plano do conteúdo é o plano onde a significação nasce das variações diferenciais graças às quais cada cultura, para pensar o mundo, ordena e encadeia idéias e discurso.[...] (Tradução livre).

Parece claro que qualquer análise que pretenda ser científica deverá levar em consideração ambos os planos. Mas, a manifestação de um desenho não se apresenta psicofisicamente para nossa visão? Ou seja, não estamos "vendo" o desenho? E quando o vemos não estamos diante de ambos os planos? Devemos estudá-los separadamente? Com essa dúvida sempre presente, fizemos o que nos pareceu mais simples: partimos do plano de conteúdo ou do sentido que podíamos "ler" de imediato, começando pela descrição do nível superficial da manifestação, tomando em consideração ambos os planos, sem nos preocuparmos em separá-los e sem a preocupação inicial de buscar o semi-simbólico que deveria considerar a forma e não a substância em ambos os planos. Vejamos, então, como ficou essa análise em outro desenho infantil com cavalo:

(Figura 2.2) JCCriança, Ehid, 8 anos

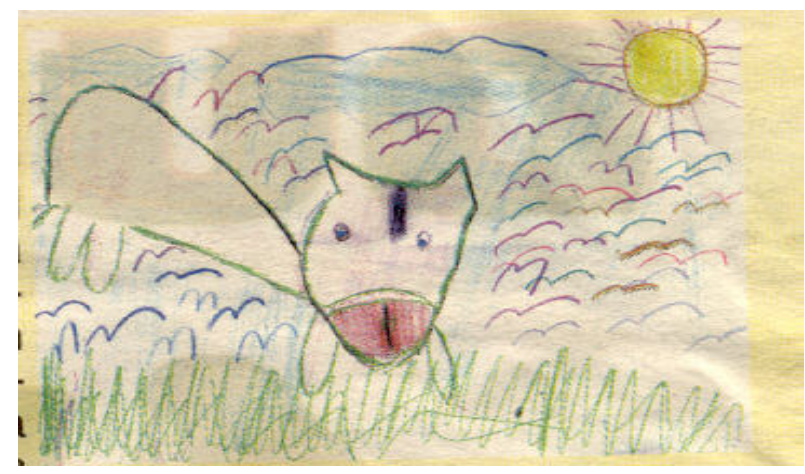

Comparando as Figuras 1.2 e 2.2, vamos procurar o que seria essencial para a figurativização do desenho de cavalos. As quatro patas? O formato do corpo? Parece que temos que concordar que é o formato da cabeça e alguns detalhes como a presença de crina, a divisão do nariz ou focinho e o formato das orelhas. Reparem que a criança em 1.2 desenhou os cavalos de perfil, utilizando apenas uma cor de lápis. Além disso, a crina estende-se pelo dorso dos cavalos como um todo e os cavalos possuem apenas três pernas. Em 2.2, a criança desenhou a cabeça animal de frente para o observador e a crina como um traço entre as duas orelhas, utilizando 
diferentes cores para distinguir o focinho do cavalo, o contorno da figura, a vegetação, o solo, o céu, o sol e, claramente, as quatro pernas do animal.

Com esse tipo de análise não chegamos a tocar no plano de expressão, pois o que fizemos foi reconhecer a aparência do que foi desenhado através do plano de conteúdo, manifestado em sua estrutura superficial, já que enxergamos reproduções do mundo natural: cavalos, crianças, patas, crina, focinho, vegetação, de perfil, de frente, colorido, etc.

Ainda tentamos nos aventurar na análise do plano de expressão, em busca do semi-simbólico e das categorias como bem explicita PIETROFORTE (2004), porém descobrimos que para isso deveríamos nos dedicar somente à análise aprofundada de um único desenho e nosso propósito sempre foi mais amplo e deveria incluir qualquer desenho de criança, em idades diferentes, em busca do que propõe o Groupe $\mu$, quando fala em descrever uma gramática geral da linguagem visual.

Ficamos nesse impasse durante algum tempo para finalmente ficarmos na análise mais modesta que vimos fazendo, detendo-nos no plano de conteúdo manifestado no que poderíamos chamar de plano superficial de expressão, por onde necessariamente temos que passar para chegar ao entendimento de como funciona a articulação entre expressão e conteúdo, em imagens desenhadas por crianças, sobre uma superfície plana.

\section{As várias maneiras de desenhar um cubo.}

A partir do posicionamento que adotamos, isto é, um olhar semiótico sobre o plano de conteúdo de um desenho infantil, vamos acompanhar a maneira como crianças em idades diferentes desenham um cubo, desde uma figura inicial, até o desenho com perspectiva. 
(Figura 1.3) In COX, 2001, página 35:

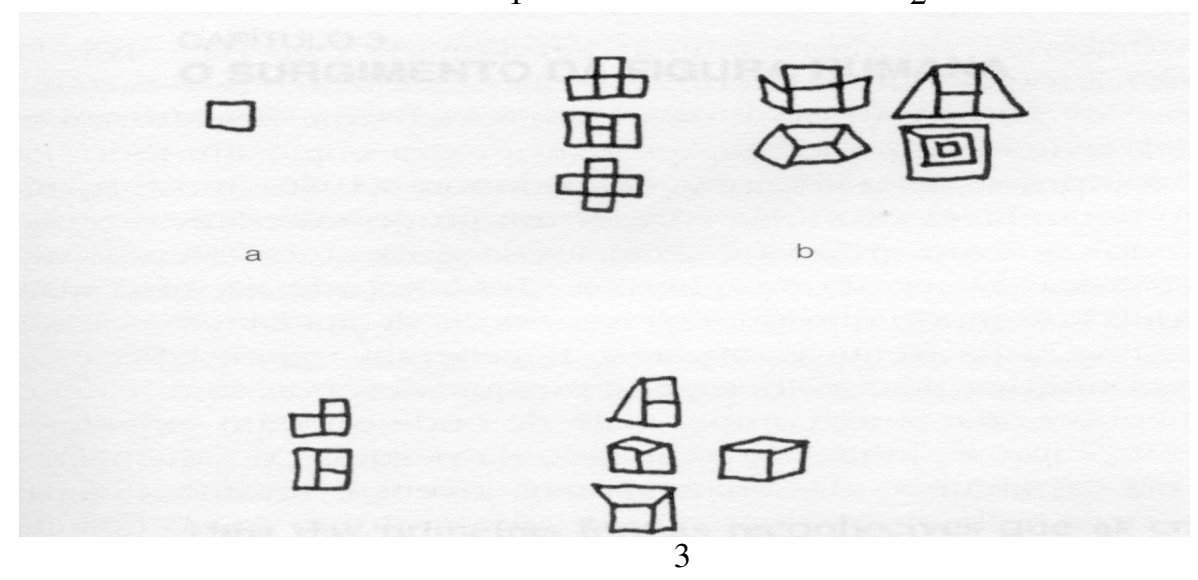

Em 1, crianças com 7 anos de idade ou menos usam com freqüência um único quadrado para representar o cubo; em 2, com 7 anos ou mais, elas procuram abrir o cubo, aplainando a figura, porém apresentam apenas quatro lados (ou três como na figura concêntrica), deixando de apresentar os demais; em 3, por volta dos 12 anos, elas tentam desenhar os três lados que realmente são vistos de um ponto de vista qualquer, mas não conseguem pois não sabem como fazê-lo usando perspectiva.

Será que as crianças chegam sozinhas ao último desenho? Quero crer que não. O mais provável é que o desenho do cubo, com perspectiva, precisa ser ensinado ou aprendido pelo indivíduo, pois é possível encontrar adultos analfabetos ou que freqüentaram poucos anos escolares que desenham o cubo de maneira semelhante aos exemplos que acabamos de observar.

Vamos então a nossa análise das etapas de construção do desenho do cubo, no seu plano de conteúdo. Podemos supor que, primeiramente, a criança olha para um cubo e, conforme o vê ou o manipula, observa que a mesma figura, o quadrado, aparece várias vezes (seis vezes), por isso desenha só um dos quadrados, numa espécie de primeiro procedimento de figuração: instalação da figura semiótica. Depois, após maior contato com o cubo (aprendizagem de figuras geométricas na escola), a criança caminha para a expansão progressiva do sentido, traço a traço, desmontando o cubo e aplainando seus lados, como se quisesse conhecê-lo por 
dentro. Em seguida, ela volta à visualização externa do sólido geométrico e desenha os três lados que realmente podem ser vistos, ainda sem a perspectiva adequada, que, conforme estamos defendendo, só pode ser ensinada e por isso aprendida.

Desse modo, estamos supondo que o Enunciador, no caso, a criança conta com a elasticidade do discurso, podendo condensar ou expandir a manifestação de seu texto, como fizeram em seus desenhos do cubo. A idéia que as línguas naturais possuem a propriedade específica de condensação e expansão encontra-se no dicionário de Greimas \& Courtés (tradução s/d:116-7), discutida e explicada por LOPES (2003:65-75), que levanta a questão de não ser possível o resumo oи a síntese de uma melodia (conforme Paul Valéry), de uma pintura ou de um desenho, mesmo porque se assim o fizéssemos teríamos outra melodia, outra pintura e outro desenho.

Portanto, o que a criança faz primeiramente é condensar a figura (só um quadrado), para depois ir expandindo o seu texto-desenho, até chegar ao cubo com a perspectiva padronizada, num novo procedimento de condensação, em que três lados são mostrados e os demais inferidos. Acreditamos que a figura final é a menos criativa, por ser a acomodação a um desenho padrão ensinado.

Esse movimento de condensação e expansão pode ser analisado como o que faz o cérebro humano diante da necessidade de representar algo através da linguagem do desenho: ou resumimos (condensamos) o que estamos vendo e fazemos esquemas ou, se temos alguma competência para desenhar, expandimos o desenho acrescentando-lhe detalhes, em busca de uma adequação aos referentes do mundo natural.

\section{Reflexões finais}

Embora a porta de entrada de qualquer linguagem seja o plano de expressão onde, no dizer de Floch, as qualidades sensíveis que uma linguagem possui para se manifestar, são selecionadas e articuladas entre si por variações diferenciais, o presente artigo destacou a questão da análise do plano de conteúdo, aplicada ao nível da manifestação, em busca de compreender como foi feito o desenho, na tentativa de explicar como a criança construiu o "parecer do sentido", sem entrar no mérito dos demais níveis, que acabariam por nos levar a um nível profundo, através da análise do semi-simbólico e de suas categorias.

Desse modo, apesar de não trazer conclusões definitivas (nem era essa nossa intenção), este trabalho desviou-se de análises de cunho pedagógico e psicológico que são comuns ao desenho infantil, introduzindo instrumental teórico próprio da 
semiótica de origem greimasiana para mostrar que é possível sua aplicação no desvendamento do como as crianças desenham.

\section{REFERÊNCIAS BIBLIOGRÁFICAS}

ASSIS SILVA, Ignácio. Figurativização e Metamorfose - O Mito de Narciso. São Paulo, Editora da Unesp, 1995.

O Projeto da Semiótica Planar. In Série Cadernos PUC, orgs. Ana Claudia de Oliveira e Lucia Santaella. São Paulo, EDUC, Editora da PUCSP, 1987.

BERTRAND, Denis. Caminhos da Semiótica literária. Tradução: Grupo Casa, EDUSC - Editora da Universidade do Sagrado Coração, Bauru, SP, 2003.

COX, Maureen. Desenho da Criança. Tradução de Evandro Ferreira, São Paulo, Editora Martins Fontes, 2001.

FERREIRA, Sueli. Imaginação e Linguagem no Desenho Infantil. Campinas, SP, Papirus, 1998.

FLOCH, Jean-Marie. Petites Mythologies de l'oeil et de l'esprit: pour une sémiotique plastique. Paris/Amsterdã, Hadès/Benjamins, 1985.

stratégies. Paris, PUF, 1990.

Sémiotique, marketing et communication: Sous les signes, les Les formes de L'empreinte. Pierre Fanlac, Périgueux, 1986.

GREIMAS, Algirdas Julien \& COURTÉS, Joseph. Dicionário de Semiótica. Tradução de Alceu D. Lima et alii. São Paulo, Editora Cultrix, s/d. GROUPE $\mu$. Traité Du Signe Visuel. Éditions du Seuil, Paris, 1992.

LOPES, Ivã Carlos. Entre Expressão e Conteúdo: Movimentos de Expansão e Condensação. Itinerários, Araraquara, n. ${ }^{\circ}$ especial, 65-75, 2003.

MOREIRA, Ana Angélica Albano. O Espaço do Desenho: A Educação do Educador. São Paulo, Edições Loyola, 1984.

OLIVEIRA, Vera Barros e BOSSA, Nádia A., orgs. Avaliação Psicopedagógica da Criança de Zero a Seis Anos. $3^{\mathrm{a}}$ edição, Petrópolis, Editora Vozes, 1996.

PIETROFORTE, Antonio Vicente. Semiótica Visual - os percursos do olhar. São Paulo, Editora Contexto, 2004. 


\section{Como citar este artigo:}

TENUTA, Adriane Ribeiro Andalo . Um olhar semiótico sobre as várias maneiras de desenhar um cubo. Estudos Semióticos, Número 1, São Paulo, 2005. Disponível em <www.fflch.usp.br/dl/semiotica/es>.

Acesso em "dia/mês/ano". 